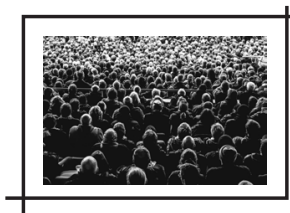

\title{
UMA OBRA, MÚLTIPLOS CRIADORES: O CINEMA COMO UMA ARTE DE AUTORIA COLETIVA
}

\author{
Luísa Pinheiro* \\ Marcos Rizolli**
}

Resumo: Este artigo pretende explorar a interdisciplinaridade inerente ao cinema e os múltiplos profissionais e saberes ligados a essa área, bem como a instabilidade existente ao se tentar enquadrar o cinema como disciplina. Para tal, serão observadas especialmente as figuras do roteirista, do diretor e dos atores. Autores como Doc Comparato, Rubens Rewald, Jaqueline Nacache e Constantin Stanislavski serão utilizados no intuito de refletir sobre a atividade cinematográfica e demandas específicas de cada uma das áreas relacionadas, explorando a coletividade atuante durante a criação de obras cinematográficas e as inter-relações que cada um dos atores investigados estabelece com os demais profissionais da indústria audiovisual.

Palavras-chave: Cinema. Interdiscipinaridade. Roteiro audiovisual. Direção cinematográfica. Atuação cênica.

\section{O CINEMA E SUA INTERDISCIPLINARIDADE INTRÍNSECA}

0 presente artigo se propõe a pensar a gênese coletiva das obras cinematográficas e audiovisuais como um todo, já que, diferentemente de outras manifestações artísticas, o cinema depende da atuação de profissionais que detêm múltiplas habilidades - um coletivo absolutamente heterogêneo, com profissionais de diferentes formações e campos de atuação.

As tensões que o cinema produz entre as disciplinas correntes já podem ser observadas inclusive no âmbito do seu ensino dentro das universidades. Se normalmente ele está alocado dentro das escolas de Comunicação, o fato é que muito da construção, por exemplo, de

\footnotetext{
* Doutoranda em Educação Arte e História da Cultura pela Universidade Presbiteriana Mackenzie (UPM). Mestra em Artes Cênicas pela Universidade Federal do Estado do Rio de Janeiro (UniRio). E-mail: Iu_pinheiro100@hotmail.com

** Pós-doutor em Artes pela Universidade Estadual Paulista "Júlio de Mesquita Filho" (Unesp). Doutor e mestre em Comunicação e Semiótica pela Pontifícia Universidade Católica de São Paulo (PUC-SP). E-mail: marcos.rizolli@mackenzie.br

1 - 0 artigo apresenta-se como parceria orientanda-orientador, sendo um desdobramento de investigação doutoral em curso no Programa de Pós-Graduação em Educação, Arte e História da Cultura da UPM.
} 
diálogos só pode ser aprendida com o auxílio de profissionais ligados ao teatro, bem como os atores utilizados nas realizações cinematográficas também são normalmente oriundos das escolas de Artes Dramáticas.

Essa fundamental heterogeneidade do objeto cinema é muito bem assinalada por Jacques Rancière em entrevista conduzida por Marie-Aude Baronian e Mireille Rosello (2008), da University of Amsterdam e Asca. No cinema há, segundo Rancière:

Uma tensão entre dois regimes: um regime de sequência narrativa e um regime de suspensão estética que está no centro do filme. Há uma mistura de regimes sensoriais. Há o fato de que o cinema é tanto o nome de um lugar, uma forma de entretenimento, uma ideia de arte etc. Há também o fato de que o cinema é algo que deve ser discutido. Não é uma biblioteca, em que todas as obras estão à nossa disposição. São imagens que passam, filmes que alguém viu e essencialmente esqueceu. As imagens são transformadas assim que são vistas, depois transformadas na cabeça das pessoas por todo um processo de seleção e, em seguida, transformadas por textos que falam sobre eles. É por isso que acho que as teorias e métodos narratológicos não são muito interessantes, porque ninguém assiste a um filme como esse (plano a plano ou unidade por unidade). A própria lógica do cinema, a do espectador, é precisamente que os elementos que ocorrem são filtrados; que as pessoas constroem seu próprio poema, seu próprio filme, com o que está diante deles; e depois o prolongam em palavras. Isso significa que o filme, assim como a literatura, não é simplesmente uma arte, mas constrói um mundo. Sobre um mundo, você não constrói alguma teoria, mas seu próprio poema (BARONIAN; ROSELLO, 2008, p. 8, tradução nossa).

Tal passagem corrobora a visão de que, mais que uma disciplina, o cinema se constitui como um campo amplo e diverso, em que convivem inúmeros saberes. Essa pluralidade é tão pungente que a própria questão de se elaborar uma teoria do cinema é vista com desconfiança por determinados estudiosos. Em declaração dada para a mesma entrevista já citada, Rancière afirma:

Eu não acredito de forma alguma na necessidade de uma teoria do cinema (mais do que uma teoria da literatura). Eu não tenho nada contra o fato de que outras pessoas afirmam construir uma. Mas a ideia de que há uma linguagem filmica, que você vai destilar os elementos dessa linguagem e que, com base nisso, você vai analisar filmes não é, na minha opinião, de muito interesse. Isso ainda pertence à ideia de disciplinas e campos, enquanto o cinema mistura diferentes regimes sensoriais: os da imaginação literária, a visão sensivel de uma pintura, a emoção musical etc. (BARONIAN; ROSELLO, 2008, p. 8, tradução nossa). 
No entanto, apesar de notadamente o cinema ser uma atividade que congrega essa diversidade de profissionais, o que configura uma interdisciplinaridade já em seu seio de realização, existe uma bibliografia bastante escassa sobre esse fato. Basicamente tudo o que é encontrado entre cinema e interdisciplinaridade tem a ver com o uso do cinema como ferramenta educacional.

Dessa forma, este trabalho pretende refletir sobre a interdisciplinaridade fundante da atividade cinematográfica e a relação entre determinados profissionais quando da elaboração de uma obra cinematográfica. Será abordada a problemática que envolve a criação de um roteiro cinematográfico e as múltiplas habilidades exigidas de um roteirista para que este possa exercer sua atividade de maneira satisfatória, a figura do diretor cinematográfico e sua interação com o roteiro e também o trabalho dos atores na construção de personagens.

Como já dito, obviamente uma produção cinematográfica conta com uma gama de profissionais muito maior do que o que será aqui abordado, como cenógrafos, figurinistas, continuístas, câmeras, produtores, editores e assistentes de toda ordem. No entanto, o recorte se deu no intuito de investigar a relação entre figuras sem as quais se torna impossivel levar a cabo uma produção audiovisual ficcional: o roteirista, o diretor e os atores.

\section{AS FUNÇÕES DO ROTEIRISTA}

São muitas as questões que envolvem a elaboração de um roteiro audiovisual, já que, apesar de este se configurar como um documento textual, sua função é evocar imagens. Ele é o primeiro passo na elaboração de um filme e o documento que servirá de base para que toda a equipe envolvida possa desempenhar sua função. Além disso, mais que contar a história, é ele que estabelece as estratégias narrativas que serão utilizadas para levar a trama para a tela.

Em se tratando de narrativas audiovisuais ficcionais, ainda que o roteiro cinematográfico configure-se como um material escrito, ele não se encaixa em nenhuma categoria literária. Apesar da necessidade de estar muito bem redigido, para que toda a equipe possa extrair dele o que necessita para o desempenho de sua função, no produto final, a obra audiovisual, o que restará desse material não necessariamente se relaciona de forma direta com as palavras impressas.

Os diálogos podem, e comumente são, bastante modificados no momento das filmagens por atores ou pelo diretor, assim como as sugestões de ação e imagens, que apenas se mantêm se corroborarem o que o resto da equipe imagina do filme. No entanto, do roteiro também advém a construção primeira dos personagens, a estrutura da obra e ainda a primeira percepção do ritmo a ser impresso na tela. Dessa forma, no material gravado e editado, tal roteiro segue coexistindo de forma oculta e, agora, como nomeia Gláucia Davino, "cristalizada" (DAVINO, 2000, p. 4). 
Esse documento é exatamente o responsável por colocar uma equipe dos mais diversos tipos de profissionais no mesmo diapasão. É ele que vai instaurar uma atmosfera e fomentar o imaginário da equipe de figurino, apontando não só a época em que se passa a obra, mas também os traços de personalidade de personagens, que fatalmente precisam estar expressos em seu vestuário. Igualmente é o roteiro que aponta para a fotografia se 0 ambiente de uma cena é soturno ou ensolarado, se é um filme denso ou mais leve. E, para a direção, sua utilidade é bastante óbvia. É exatamente a partir do roteiro que um diretor exerce sua criação, compreendendo o universo com que vai trabalhar, para assim poder fazer suas escolhas.

Se a dramaturgia teatral tem enorme liberdade em sua formatação, podendo um texto teatral apresentar ou não rubricas e até mesmo optar por não deixar claro quiçá o local onde se passa a ação, permitindo que atores e diretores façam opções no momento da montagem, isso no cinema é impossível. É preciso que tudo seja muito bem especificado para que possa ser produzido, inclusive porque, de maneira mais contundente do que no teatro, qualquer deslize pode significar muitos gastos financeiros em vão.

0 roteiro se configura, então, como um texto cinematográfico e também como uma das etapas da produção de um filme que vai balizar todas as seguintes. É no roteiro que estará impresso todo o conteúdo de uma obra, e também é ele o principal instrumento de venda de um filme para produtoras ou estúdios, já que, a partir de sua elaboração, também é possivel desenvolver um orçamento para o projeto em questão. De acordo com o roteirista Doc Comparato $(2009$, p. 29),
[...] de maneira muito geral podemos dizer que essa forma escrita que chamamos de roteiro é algo muito efêmero. Existe durante o tempo que leva para se converter num produto audiovisual. Embora haja roteiros editados em forma de livro, atualmente existem coleções ou sites dedicados a isso, o roteiro propriamente dito é como se fosse uma crisálida que se converte numa borboleta, imagem proposta por Suso d'Amico, a grande roteirista italiana.

Dessa forma, o roteiro não tem um fim em si. Ele é um material que mistura uma escrita técnica e dramática e que tem utilidade até que uma obra cinematográfica seja gravada, editada e chegue finalmente ao público. Outra questão que distingue terminantemente 0 roteiro audiovisual de gêneros literários é o fato de que na literatura há apenas um ou poucos criadores envolvidos no processo de elaboração de uma obra, ao passo de que a feitura de um roteiro está ligada diretamente à indústria do audiovisual. Ainda que apenas um roteirista assine um filme, normalmente os responsáveis por seu financiamento têm amplo controle naquilo que se configurará como produto final.

Sobre as múltiplas funções que o roteiro exerce em uma produção, o roteirista Bráulio Mantovani, em entrevista a Lucas Paraízo (2014, p. 25), assinala que: 
0 roteiro é o filme no papel. É a descrição das imagens, das ações e das falas dos personagens em um texto. Uma espécie de ensaio do que vai ser o filme. 0 roteiro cinematográfico não tem a mesma autonomia literária que, por exemplo, uma obra teatral. Ele pode ir para o lixo quando acaba as filmagens; não serve para nada, a não ser para ser estudado por pessoas que querem aprender a fazer roteiro [...] Outro papel importante do roteiro é seduzir potenciais financiadores. Cinema é uma coisa muito cara, então, se o filme não estiver muito bem escrito, de maneira que seja gostoso de ler, prazeroso, e que envolva o leitor tanto quanto um romance é capaz de envolver, será mais difícil realizá-lo. No Brasil, hoje em dia, você só capta recursos para fazer um filme a partir de um roteiro. Isso está cada vez mais evidente.

A passagem salienta que nessa indústria toda a criação acontece de forma coletiva e segmentada, resultado da articulação de inúmeros profissionais, tecnologias e decisões corporativas. Assim, o cinema configura-se como local onde arte e negócios se mesclam e as disputas entre ambos são a tônica de todo o processo criativo. Nessa perspectiva, o imaginário evocado por um filme tem sua espinha dorsal estabelecida pelo roteiro, mas em muito é modificado ao longo do processo de filmagem e pós-produção, ganhando novas camadas nas inúmeras etapas de produção por que passa uma obra cinematográfica.

São tantas as mãos que manipulam esse documento, que ele precisa ser desenvolvido a partir de uma escrita muito particular. Se uma formatação precisa é fundamental, já que todos precisam compreender rapidamente as informações que precisam extrair, tal escrita não pode de maneira nenhuma ser fechada. Ela precisa fomentar a imaginação sem oferecer demasiadas respostas ou indicações para tudo. Um roteiro tem que inspirar todos os demais profissionais da equipe, mas sem entrar demasiadamente em suas áreas de atuação.

Com tantas atribuições e limitações impostas a um roteirista em seu trabalho na indústria audiovisual, é de se imaginar a grande quantidade de habilidades que um profissional da área precisa desenvolver para poder desempenhar com sucesso seu ofício. Se a própria área do cinema já possui vocação interdisciplinar, a um roteirista igualmente é solicitado um trânsito entre diferentes esferas e conhecimentos quando da elaboração de sua obra.

Desenvolver um roteiro audiovisual é tarefa que exige constante preocupação em diversas instâncias. Primeiramente, ao roteirista é solicitado uma visão do todo, já que a integralidade da obra cinematográfica precisa estar contida nesse documento, que se configura como grande articulador dos diversos criadores envolvidos em um filme. 0 roteirista precisa ter domínio sobre o discurso da obra, seja em termos de linguagem ou das múltiplas camadas interpretativas e do jogo de tensões que a construção de um filme solicita. Nesse sentido, seu trabalho se aproxima bastante dos conhecimentos desenvolvidos no campo da Comunicação Social e seus estudos acerca da linguagem, seus efeitos, suas capacidades de significação e construção de sentidos. 
A partir do roteiro, como já mencionado, diversos outros profissionais são convocados para seguir com a construção do que será a obra cinematográfica descrita naquele documento. Boa parte dessa mão de obra será selecionada de acordo com a visão artística e com as pretensões daquele que age como um maestro de toda empreitada cinematográfica, coordenando todos os demais: o diretor.

\section{A DIREÇÃO CINEMATOGRÁFICA}

É a partir dos anos 1950 que a figura do diretor emerge como a grande responsável pela obra cinematográfica. Exatamente quando têm início as discussões acerca da autoria no cinema, partindo da preocupação de alguns críticos dos Cahiers du Cinéma², os diretores reivindicam a posição de responsáveis principais pela criação de um filme. Dessa forma, tal busca pela autoria:

[...] fez do diretor a figura principal na produção de filmes. Como consequência, a criação de um filme passou a ser cada vez mais considerada uma criação individual, em vez de coletiva. As contribuições dos atores, juntamente com os fotógrafos, editores, gravadores de som, criadores de produção, etc., foram subordinadas ao gênio do diretor (LOVELL; KRAMER, 1999, p. 2, tradução nossa).

No Brasil da época, tais discussões igualmente encontraram eco. Surgia no periodo o movimento do Cinema Novo, com Glauber Rocha como uma de suas mais emblemáticas figuras. Em seu trabalho, Glauber centralizava de tal forma a criação, que filmava praticamente sem um roteiro. A dramaturgia de suas obras:

Brotava da câmera, de seus jogos com os atores, de sua visão política e trágica do mundo. Várias vezes o filme estava em sua mente, havia só um argumento, alguns fiapos de cenas escritos, e ele jogava com isso, fazia desse desconhecimento da equipe um mote para a criação (REWALD, 2009, p. 286-287).

É a partir da década de 1970 que a produção cinematográfica brasileira começa a ficar mais institucionalizada, com produções mais ambiciosas e de maior orçamento. A partir desse momento, o roteiro passa a ser peça-chave para a viabilização de um filme. Tal necessidade de um roteiro ocorre não apenas pelo direcionamento das gravações, mas também 
para que a Embrafilme, entidade que centralizava o financiamento cinematográfico no Pais, tomasse conhecimento do que se tratava o filme e aportasse dinheiro à produção. Surgem, então, os primeiros roteiristas profissionais no Brasil, mas a figura do diretor continua central em todo o processo.

Essa centralidade da figura do diretor se mantém, provavelmente, na maior parte das produções cinematográficas da atualidade. Em suma, apesar das especificidades de cada profissional envolvido na cadeia do audiovisual, é o diretor que irá conduzir o elenco e a equipe, direcionando os resultados por meio de sua visão artística. Dessa forma, ele é especialmente o profissional que colhe os louros de um eventual sucesso ou é responsabilizado por algum fracasso.

Apesar do volume de atribuições desse profissional, que cria grande sensação de poder, é preciso lembrar que há instâncias que limitam a atuação de um diretor. A produtora ou estúdio responsável pelo filme, patrocinadores e toda a cadeia de financiamento de uma obra audiovisual têm, muitas vezes, autonomia para frear ideias, modificar cenas e exigir readequações por questões orçamentárias. Apesar de contar com um grande maestro, por sua caracteristica de indústria, o audiovisual definitivamente não permite ao diretor um poder sem limites.

Um exemplo de tais limitações no Brasil foram as décadas de 1940 e 1960. No momento em que a produção cinematográfica era calcada no modelo dos grandes estúdios, a exemplo do modelo estadunidense, a Cinédia, a Vera Cruz, a Atlântida e a Maristela ditavam tanto a dramaturgia quanto o modo de encenação. 0 público, muitas vezes, não sabia de quem era o roteiro ou a direção da obra, mas a assinatura do estúdio responsável estava sempre muito clara.

Ainda que o maior volume de produções da atualidade tenha o diretor como figura central, é sempre importante lembrar que um diretor não trabalha sozinho, e seu sucesso vem muitas vezes pela capacidade de ouvir os profissionais que estão ao seu redor. No caso do roteiro, por exemplo, ele é o primeiro elemento a ser apreciado pela direção. É ele que irá inspirar o diretor na definição do estilo de fotografia do filme, movimentos de câmera, luz das cenas, figurinos e adereços. Compreender e dialogar com a visão e as intenções do roteirista em cada indicação cênica é fundamental para a construção de um filme.

Assim, o roteirista trabalha com elementos que serão absorvidos e transformados pelo diretor e sua equipe no momento das filmagens. Porém, essas transformações não cessam ai. 0 montador, de posse de tudo o que foi gravado, opera um novo momento de mudanças, muitas vezes reescrevendo passagens do roteiro, omitindo trechos gravados etc. Esse trabaIho de montagem é igualmente supervisionado pelo diretor, responsável por colocar o ponto final na obra.

Há também algumas experiências que mostram outras maneiras de se lidar com a dramaturgia no cinema. 0 diretor Mike Leigh, por exemplo, não desenvolve um roteiro para seus 
filmes. A partir de ideias ou sensações iniciais, ele trabalha em um processo de ensaios com a equipe e os atores. Ali é elaborado o roteiro, que muitas vezes nem chega ao papel.

Ao descrever o trabalho de Leigh, Rubens Rewald aponta que o processo do diretor em muito se assemelha com o que comumente se observa em montagens teatrais, especialmente as que não se baseiam em textos dramáticos tradicionais. Segundo o autor:

Seu processo de trabalho consiste num extenso periodo de ensaios em que as ideias principais de Leigh são discutidas, pesquisadas e improvisadas pelos atores. As futuras cenas do filme vão sendo elaboradas por Leigh nos próprios ensaios, a partir do material levantado pelos atores. Tudo é criado nesse momento, os diálogos, a movimentação e, inclusive, o subtexto dos personagens (REWALD, 2009, p. 287-288).

Tal estratégia gera, normalmente, grandes dificuldades para o financiamento de uma obra, já que impede que se tenha a priori qualquer tipo de controle ou garantia acerca do que será o filme e mesmo se ele será de fato realizado. Se hoje o diretor, por sua sólida carreira, consegue driblar tais problemas, sua estratégia autoral trouxe grandes desafios no princípio de sua trajetória no cinema.

Os altos custos de produção de um filme muitas vezes inviabilizam a ideia de work in progress, muito comum no teatro. Outra questão que dificulta seriamente esse tipo de trabalho é a própria característica do suporte, que impede novas modificações após as filmagens. Se no teatro um espetáculo pode continuar sendo trabalhado até a última apresentação, no cinema essa possibilidade não existe. 0 último período de modificações de uma obra cinematográfica é o da montagem.

No entanto, mesmo no Brasil existem experiências que investem em processos mais colaborativos para a construção de uma obra. Um grande exemplo é o filme Cidade de Deus, de 2002, com direção de Fernando Meirelles e Katia Lund. Baseando-se na obra homônima de Paulo Lins, o roteirista Bráulio Mantovani desenvolveu uma primeira versão do roteiro. A partir de inúmeras discussões com Fernando Meirelles, tal versão foi retrabalhada, dando lugar a mais algumas versões.

Após essa primeira etapa de trabalho, vieram os ensaios com os atores, a maioria sem experiência prévia. Tais ensaios contaram com o auxílio da preparadora de elenco Fátima Toledo e foram diretamente acompanhados por Bráulio Mantovani, que, a partir das falas e ações improvisadas durante o processo, desenvolveu novas versões do roteiro.

Esses não são, definitivamente, os únicos exemplos de diretores que optaram por flexibilizar seu modo de atuação na indústria cinematográfica. Cada vez mais a noção de processo está, de alguma maneira, presente no trabalho de diretores e também de roteiristas. Nesse sentido, tais práticas apontam caminhos alternativos à rígida hierarquização da atividade cinematográfica e à demasiada concentração de poder nas mãos do diretor. 
As obras provenientes de tais metodologias de trabalho são fruto, então, de uma criação compartilhada, em que todos os envolvidos têm a possibilidade de influenciar decisivamente o resultado final. Nesse sentido, o roteirista, que normalmente não participa da etapa de filmagens, sai do escritório e passa a criar uma dramaturgia viva, que acompanha o processo de desenvolvimento da cena.

Seja nesse modelo de trabalho ou mesmo nos mais tradicionais, ainda que o diretor tenha a palavra final em muitos aspectos, quando se trata de fiç̧ão, é impossivel não levar em conta a importância dos atores e suas habilidades criativas na construção de uma obra cinematográfica. Por mais que o diretor tenha determinada visão dos personagens, são os atores que trazem corpo a eles e, para tal, necessitam de metodologias de trabalho bastante particulares.

\section{O TRABALHO DO ATOR}

Uma das primeiras questões a se levantar acerca dos atores e da construção de personagens em uma obra audiovisual por parte dos atores, especialmente no Brasil, é a escassa bibliografia ou conjunto de técnicas especialmente voltadas para este meio no que tange ao trabalho de atuação. À exceção de alguns preparadores de elenco norte-americanos, ainda não traduzidos para o português, e especialmente dos desdobramentos para o cinema hollywodiano dos trabalhos de Lee Strasberg e Stela Adler, praticamente toda a literatura acerca do trabalho do ator está contida em obras que levam em conta o teatro.

Dessa maneira, diferente da relação que outros profissionais da indústria audiovisual estabelecem com o universo teatral, os atores, em seus estudos, evocam a todo tempo o teatro como referência na construção de seus personagens para o cinema ou televisão. Assim, se um diretor cinematográfico tem a gênese de seu trabalho bastante isolada da estética teatral, o mesmo ocorrendo com figurinistas, iluminadores cênicos e mesmo dramaturgos, os atores a todo tempo se apropriam das referências teatrais na execução de seu trabalho no meio audiovisual.

Por outro lado, se os estudos sobre atuação esquecem o audiovisual, os estudos sobre cinema igualmente não colocam muita luz sobre o trabalho do ator. Nos estudos sobre teatro, a figura do ator é sempre uma questão central, porém, no cinema isso não se dá. Estudam-se a direção, o roteiro, a luz, os figurinos. Quase todo o resto da cadeia produtiva torna-se objeto de investigação, mas não os atores. É como se tal trabalho estivesse completamente apartado do processo produtivo, o que os aproxima uma vez mais de uma abordagem do papel próxima ao teatro.

Partilhando dessa percepção, Jacqueline Nacache (2012) reforça a grande distância existente entre o estudo acerca do trabalho do ator e das demais funções na cadeia do cinema. Segundo a autora: 
[...] os estudos cinematográficos estão ocupados pelos seus objetivos dominantes: a abordagem das obras, dos cineastas, das influências, dos estilos; a abordagem do cinema como linguagem, como narrativa, como arte visual e sonora. 0 ator parece ter pouco a ver com esta aventura (NACACHE, 2012, p. 7).

Dessa forma, partindo da dificuldade em se falar de técnicas de atuação pensadas diretamente para o cinema, torna-se necessário, para atores e estudiosos, acessar uma bibliografia oriunda do teatro, mas que é igualmente utilizada na preparação de muitos atores no universo audiovisual, começando pelo encenador russo Constantin Stanislavski.

Stanislavski foi o primeiro a elaborar uma metodologia de trabalho especifica para o ator, podendo seu trabalho ser dividido em duas frentes: o trabalho do ator sobre si mesmo e o trabalho do ator sobre o personagem. Nesse sentido, o primeiro torna-se condição obrigatória para o segundo. Assim, o trabalho do ator tem início a partir de si, com a evocação de suas próprias experiências e individualidade. Segundo ele:

No trabalho o ator deve sempre começar de si mesmo, da própria qualidade natural, e então continuar de acordo com as leis da criatividade [...]. A arte começa quando não existe papel, existe somente o "eu" em uma dada circunstância da peça [...]. 0 ator realmente atua e vive seus próprios sentimentos: ele toca, cheira, ouve, vê com toda a finesse de seu organismo, seus nervos; ele verdadeiramente atua com eles (TOPORKOV, 2016, p. 156).

Dessa forma, caberia ao ator, inicialmente, se aproximar do personagem buscando colocar-se em situação equivalente à dele, envolvendo sua natureza inteira: física, intelectual, emocional e intelectual, nesse propósito. Com essa abordagem inicial de trabalho, Stanislavski se distancia de uma ideia de que o ator se transmuta em um personagem, como se pudesse abandonar o indivíduo em prol do trabalho de atuação.

Estabelecendo que tudo o que o ator cria é a partir de si mesmo, isso independe da estética ou das escolhas do diretor, podendo ser aplicado tanto no teatro quanto em qualquer outro meio que possibilite o trabalho de atuação. Tal metodologia de trabalho igualmente permite que o ator se torne uma potência criadora em si, ficando menos dependente de instruções externas para levar a cabo seu trabalho.

No início de suas pesquisas, o encenador russo buscou elaborar exercícios que ativassem o que chamava de memória emotiva, que seria a busca por emoções análogas às do personagem para a elaboração da cena, e também o que intitulava o se mágico, ou a capacidade do ator de colocar-se na situação vivenciada pelo personagem. Para tal, desenvolveu exercícios como o que relata a seguir: 
Passe em torno de diferentes objetos usando o "como se" para mudar o seu relacionamento com eles. E se esse copo de água fosse veneno? E se esse cinzeiro de vidro fosse um sapo? E se esse livro fosse uma bomba? (STANISLAVSKI, 1989, p. 99-100).

Já no final de suas pesquisas, Stanislavski faz uma profunda revisão de suas afirmações anteriores, ao perceber que o subconsciente, por sua natureza abstrata, jamais poderá estar sob o controle do ator. Nessa fase, o autor passa a chamar a memória emotiva de memória corporal, e dá um grande passo em direção ao Método das Ações Físicas, posteriormente desenvolvido por Jerzy Grotowski. Assim, a abstração das emoções começa a dar lugar à concretude das ações físicas.

Continuando a pesquisa acerca das ações físicas, Jerzy Grotowski é outro nome fundamental quando se trata do trabalho do ator. Thomas Richards, em seu Trabalhar com Grotowski sobre as ações físicas, aponta que, segundo o diretor, seriam as ações físicas as capazes de "preparar o terreno" e "colocar os trilhos" (RICHARDS, 2012, p. 66) para que os atores possam desempenhar de maneira satisfatória o seu trabalho.

As investigações de Stanislavski também chegaram a profissionais dos Estados Unidos, e pode-se considerar que revolucionaram a maneira como se pensava a atuação até então, inicialmente para o teatro e, em seguida, para o cinema. A apreensão de tais técnicas por profissionais estadunidenses gerou o que posteriormente ficou conhecido como 0 Método, responsável por importantes impactos na produção cinematográfica norte-americana em um dos grandes momentos de expansão dessa indústria.

Três foram as abordagens que se seguiram a partir das investigações de Stanislavski e sua assimilação por profissionais dos Estados Unidos, cada uma capitaneada por um egresso do Group Theater $^{3}$ : Lee Strasberg, Stella Adler e Sanford Meisner. Os distintos caminhos trilhados por cada um deles podem ser resumidos como:

0 de Strasberg (Actors Studio) com maior ênfase na psicologia, na verdade e na emoção; 0 de Adler (Stella Adler Conservatory) com ênfase na dramaturgia, na imaginação e nas ações fisicas; e o de Meisner (Neighborhood Playhouse) com enfoque no comportamento humano, nas relações e na realidade do fazer (HODGE, 2010, p. 144, tradução nossa).

Em todas as investigações citadas, desde Stanislavski (1989) e Grotowski (1987) até os profissionais que fundaram e desenvolveram 0 método nos Estados Unidos, há em comum o fato de que o ator é visto como uma potência criadora, que colabora com o todo da obra, e não como uma marionete da direção. Em relação ao cinema, um caso emblemático, que

3 - Importante companhia de teatro de Nova York fundada em 1931. 
reforça tal visão, é a relação entre o ator Marlon Brando e o diretor Elia Kazan, tanto na montagem teatral, realizada em 1947, quanto na versão cinematográfica, do ano de 1951, de Streetcar named desire, traduzido para o português como Um bonde chamado desejo, da obra de Tennessee Williams.

David Richard Jones (1986), em seu livro Great directors at work, apresenta um depoimento de Kazan sobre o trabalho com Marlon Brando:

Ele estava em outro nível. Havia algo milagroso nele, eu explicava o que estava em minha mente, e ele escutava, mas sua escuta era tão plena que falar com ele era uma experiência incrivel; ele não respondia imediatamente, mas ia embora e fazia algo que muitas vezes me surpreendia. Você tinha essa sensação: "Deus, isso é melhor do que o que eu disse a ele! Oh, eu estou tão agradecido por ele ter feito isso!" É como se ele estivesse oferecendo um presente. Era essencialmente o que Ihe pedira, mas o sentimento era tão verdadeiro, tão re-experimentado por meio de seu próprio mecanismo artístico. É quase como dirigir um animal genial... ele até surpreende os outros atores. Às vezes você nem sabe que ele está atuando, ele faz algo e você diz: "Oh, sim, ele está! Ele está fazendo isso!". Ele é muito, muito underground - você não sabe como ele consegue o que consegue. Parte disso é intuição, parte é inteligência real, parte é a capacidade de ser empático - ele se conecta com as pessoas (JONES, 1986, p. 149, tradução nossa).

A postura de Marlon Brando em relação ao seu trabalho igualmente fornece importantes pistas em relação à lida dos atores com a dramaturgia e, especialmente nesse caso, com o roteiro audiovisual que Ihes chega à mão. Em sua biografia, Brando afirma que:

Se o ator está trabalhando com um diretor que não tem bom gosto ou que é perigosamente inseguro, precisa assumir o controle e garantir que a cena seja bem-feita; na realidade, o ator tem de dirigir a cena. [...]. Há vezes em que o ator improvisa e melhora a história e o espírito da peça, mas isso nem sempre acontece. Se o ator está interpretando algo de Tennessee Williams, convém se ater ao roteiro; mas a maioria dos roteiros não é escrita em pedra, portanto podem ser modificados e ficar mais cômodos para o ator. De vez em quando deparamos com um roteiro que não é muito bom, mas o diretor acha que é. Convém evitar esse tipo de situação a qualquer custo, desde o início (BRANDO; LINDSEY, 1994, p. 172).

A partir dessa passagem, é possível aferir que o ator não defende interferências gratuitas no texto, já que inclusive defende que, se bem escrito, ele deve ser seguido. Porém, o que reivindica é uma posição de decisão, na qual ao ator também cabe fazer escolhas em prol de uma cena bem realizada. Dessa maneira, assim como as teorias aqui abordadas, Brando cor- 
robora a visão de um ator que é também cocriador de uma obra, seja ela voltada para o teatro, seja para o cinema.

\section{CONCLUSÃO}

Dar conta da complexidade da indústria cinematográfica, em que inúmeros profissionais compõem uma vasta e segmentada equipe de criação, é missão bastante trabalhosa. Se em outras manifestações artísticas a atribuição de autoria em relação a uma obra pode ser relativamente simples, no cinema a criação e a produção de narrativas surgem da interconexão entre vários atores, cada um atribuindo à obra cinematográfica determinada camada de significação de acordo com seu ofício.

Com isso, torna-se possivel apreender que o processo de elaboração de um filme ou de uma obra audiovisual passa obrigatoriamente por uma noção de interdisciplinaridade, ainda que o cinema normalmente seja considerado uma área de estudos com certa coesão. Rancière faz importante apontamento acerca da convivência entre dois universos no cinema, o narrativo e o técnico:

\footnotetext{
[...] por um lado, em efeito, o cinema é a arte que acabou por levar a cabo o programa da revolução estética. Para os teóricos da década de 1920, o cinema era a arte que havia chegado para se livrar da narrativa e da psicologia do velho estilo, de modo a transmitir os eventos da matéria sensorial - o cintilar de átomos de luz em uma tela. Era a arte da máquina que deveria nos libertar da figura clássica do artista e nos fazer abandonar as figuras e formas clássicas da narração e da psicologia. Era a arte da luz e do movimento falando por si mesmos. Como se viu, o cinema fez algo bem diferente, porque reintroduziu formas de narração e psicologia que foram destruídas em outros lugares e até mesmo a distribuição em gêneros (BARONIAN; ROSELLO, 2008, p. 7-8, tradução nossa).
}

Fica clara, então, a coexistência entre duas instâncias que se misturam na produção cinematográfica: a estética e a narrativa. E se o próprio cinema já apresenta tais questões em seu enquadramento como área ou disciplina, certa noção de interdisciplinaridade também pode ser observada no fazer daquele responsável pela dramaturgia de uma obra audiovisual, o roteirista.

Inicialmente, é importante lembrar que a narrativa cinematográfica passa por dois momentos quando da elaboração de uma obra audiovisual. 0 primeiro se dá no trabalho do roteirista, que precisa forjar toda a espinha dorsal do que será o filme e ter ligação direta com o estúdio, os produtores ou aqueles responsáveis por financiar a produção em questão. Dessa maneira, já no início de seu trabalho, sua criação convive com as limitações e com os interesses comerciais dos responsáveis pelos aportes financeiros. 
Em seguida, com o roteiro já finalizado e no momento das filmagens e da edição, a narrativa passa por outros períodos de modificação, nos quais cada criador, dentro de suas especialidades, agrega novos elementos e camadas de significação à obra. Dessa maneira, tais etapas não se constituem apenas como uma materialização do roteiro audiovisual em sons e imagens, mas também como etapas de intensa criação.

Assim, o roteiro não se configura como um manual, detentor completo de todas as informações e etapas de produção de uma obra. Ele funciona como um guia que estabelece a estrutura narrativa a ser utilizada tanto como elemento para a venda de um projeto para realizadores e patrocinadores quanto para direcionar todas as etapas seguintes até a finalização do filme.

De posse desse documento, outros profissionais começam a agregar à obra cinematográfica suas camadas de criação e, igualmente, de autoria. 0 diretor, como grande maestro do fazer audiovisual, faz suas escolhas criativas e coordena todo o restante da equipe. Dele vêm as decisões finais em relação aos demais setores. No entanto, esse poder tampouco é ilimitado, já que, em última instância, para que um filme consiga verbas para sair do papel, deve estar vinculado a estúdios e/ou produtoras. E os detentores do dinheiro comumente exercem grande poder nessas relações.

0 diretor também pode optar por desempenhar seu papel de maneira menos centralizadora, em processos que muitas vezes se assemelham aos das montagens teatrais. Nesse caso, não é incomum encontrar diretores que organizam salas de ensaio com os atores de seus filmes e colocam o roteirista para registrar momentos de improvisação para que, eventualmente, possam constar no roteiro final. Também há ocasiões em que o roteiro é integralmente redigido a partir dessa mecânica de criação. Nesses casos, a problemática em relação à autoria da obra ganha ainda mais nuances.

Em relação aos atores, poucos são os estudos cinematográficos que contemplam o trabaIho de atuação. Da mesma maneira, os manuais de atuação tampouco dão grande atenção para o meio audiovisual, focando essencialmente a atividade teatral. Uma das motivações para isso se dar provavelmente é a noção de que atores, mais do que criar, executam determinada visão da direção. Porém, isso definitivamente pode ser contestado.

Seja nos estudos de Stanislavski (1989) ou Grotowski (1989), especificamente voltados para o teatro, seja na sua apreensão pelos profissionais estadunidenses desenvolvedores d'O Método, os atores são vistos como potências criadoras. Um profissional que também faz escolhas a partir dos materiais que recebe, que colabora criativamente com a produção e que consegue inserir novas camadas de significação na obra.

Dessa forma, é possivel aferir que são diversas as tensões existentes tanto no estudo quanto na prática do cinema, em relação aos diversos profissionais, com distintas formações e habilidades necessárias para a realização de uma obra. Apesar de ser comumente denominado área, o cinema exige um constante diálogo entre saberes, o que o torna um local onde há um evidente exercício de interdisciplinaridade. 


\title{
One film, multiple creators: cinema as an art of collective authorship
}

\begin{abstract}
This article intends to explore the interdisciplinarity inherent to cinema and the multiple professionals and knowledge linked to this area, as well as the instability that exists when trying to frame cinema as a discipline. To this end, the figure of the screenwriter, director and actors will be especially observed. Authors such as Doc Comparato, Rubens Rewald, Jaqueline Nacache and Constantin Stanislavski will be used in order to reflect on the cinematographic activity and specific demands of each of the related areas, exploring the collective creation during the cinematographic works and the interrelationships that each professional establish with rest of the audiovisual industry.
\end{abstract}

Keywords: Movies. Interdisciplinarity. Screenplay. Film direction. Acting.

\section{REFERÊNCIAS}

BARONIAN, M.-A.; ROSELLO, M. Jacques Rancière and indisciplinarity. Art \&t Research: A Journal of ldeas, Contexts and Methods, v. 2, n. 1, p. 1-10, 2008.

BRANDO, M.; LINDSEY, R. Brando: canções que minha mãe me ensinou. São Paulo: Siciliano, 1994.

CIDADE DE DEUS. Direção: Fernando Meirelles e Kátia Lund. Intérpretes: Alexandre Rodrigues, Leandro Firmino da Hora, Phellipe Haagensen, Douglas Silva, Jonathan Haagensen, Matheus Nachtergaele, Seu Jorge. Rio de Janeiro: 02 Filmes: Globo Filmes Videofilmes, 2002. 1 DVD (130 min), color.

COMPARATO, D. Da criação ao roteiro. São Paulo: Summus, 2009.

DAVINO, G. Roteiro, elemento oculto no filme: filme, a cristalização do roteiro. 2000. Tese (Doutorado em Ciência da Comunicação) - Escola de Comunicações e Artes, Universidade de São Paulo, São Paulo, 2000.

GROTOWSKI, J. Em busca de um teatro pobre. Tradução Aldomar Conrado. Rio de Janeiro: Civilização Brasileira, 1987.

HODGE, A. Actor training. Londres: Routledge, 2010.

JONES, D. R. Great directors at work. Califórnia: University of California Press, 1986.

LOVELL, A.; KRAMER, P. (ed.). Screen acting. Londres: Routledge, 1999.

NACACHE, J. $O$ ator de cinema. Lisboa: Texto \&t Grafia, 2012.

PARAízO, L. Palavra de roteirista. São Paulo: Editora Senac, 2014. 
REWALD, R. Dramaturgia: o texto e tudo mais ao redor. São Paulo: Sala Preta, 2009. v. 9, p. 281-291.

RICHARDS, T. Trabalhar com Grotowski sobre as ações físicas. São Paulo: Perspectiva, 2012.

STANISLAVSKI, C. Minha vida na arte. Rio de Janeiro: Civilização Brasileira, 1989.

TOPORKOV, V. Stanislavski ensaia: memórias. São Paulo: É Realizações, 2016. 